AperTO - Archivio Istituzionale Open Access dell'Università di Torino

\title{
Time Trends in Bullying Behavior in Italy
}

\section{This is the author's manuscript}

Original Citation:

Availability:

This version is available http://hdl.handle.net/2318/1523128

since 2015-08-26T12:54:23Z

Published version:

DOI:10.1111/josh.12269

Terms of use:

Open Access

Anyone can freely access the full text of works made available as "Open Access". Works made available under a Creative Commons license can be used according to the terms and conditions of said license. Use of all other works requires consent of the right holder (author or publisher) if not exempted from copyright protection by the applicable law. 
This is the author's final version of the contribution published as:

Vieno, Alessio; Lenzi, Michela; Gini, Gianluca; Pozzoli, Tiziana; Cavallo, Franco; Santinello, Massimo. Time Trends in Bullying Behavior in Italy. THE JOURNAL OF SCHOOL HEALTH. 85 (7) pp: 441-445.

DOI: $10.1111 /$ josh.12269

The publisher's version is available at:

http://doi.wiley.com/10.1111/josh.12269

When citing, please refer to the published version.

Link to this full text:

http://hdl.handle.net/2318/1523128 
Running Head: bullying trend in Italy

\title{
Time trends in bullying behaviour in Italy
}

\author{
Alessio Vieno (contact person) \\ alessio.vieno@unipd.it \\ Department of Developmental and Social Psychology, University of Padova \\ Via Belzoni 80, 35131 Padova, Italy \\ Tel. ++39049 8278479; Fax. ++390498278451 \\ Michela Lenzi \\ michela.lenzi@unipd.it \\ Department of Developmental and Social Psychology, University of Padova
}

Via Belzoni 80, 35131 Padova, Italy

\author{
Gianluca Gini \\ gianluca.gini@unipd.it
}

Department of Developmental and Social Psychology, University of Padova

Via Venezia 8, 35131 Padova, Italy

\author{
Tiziana Pozzoli \\ tiziana.pozzoli@unipd.it
}

Department of Developmental and Social Psychology, University of Padova Via Venezia 835131 Padova, Italy 


\section{Franco Cavallo}

franco.cavallo@unito.it

Department of Public Health and MicrobiologyPaediatrics, University of Torino

Via Santena, 5-bis, 10126 Torino, Italy 


\section{Time trends in bullying behaviour in Italy}

Objectives: To identify trends over 8 years in prevalence of bullying and associated victimization among Italian adolescents. Moreover, gender differences in the trends of adolescent bullying and victimization were explored.

Methods: The survey reported here is part of the larger cross-sectional (2002/2006/2010) "Health Behaviour in School Aged Children" (HBSC) trans-national study. The sample was comprised of 13,174 Italian middle and secondary school students (11-15 year olds; 50.3\% girls). Data were collected through a self-report questionnaire. Measures included involvement in bullying as either a perpetrator or a victim. Trends were determined using the Gamma statistics. Results: Consistent and robust decreases in the prevalence of bullying between 2002 and 2010 were detected in Italy. The phenomenon "split in half" |u 1$]$ in 8 years in both chronic and occasional bullying and victimization, and the decrease resulted similar for both gender groups. Conclusions: Study findings demonstrated a strong decrease in involvement in bullying behaviour in Italy, in particular after 2006, when the Italian government invested more systematically in the prevention effort on bullying. This is encouraging news for policy-makers and practitioners working in the field of bullying prevention.

Keywords: adolescence; bullying; time trend; gender difference; Italy 


\section{Introduction}

In the last two decades, school bullying has become a great concern for health professionals, educators and psychologists, and teachers and families alike. The increasing attention to this phenomenon is mainly due to its adverse consequences for children's and adolescents' psychosocial adjustment (Nansel et al. 2001; Vieno et al. 2011; for meta-analyses see Reijntjes et al. 2010; Ttofi et al. 2011), psychosomatic health (Fekkes et al. 2006; for metaanalyses see Gini and Pozzoli 2009, 2013), and medicine use (Due et al. 2007).

Even though it is somewhat difficult to compare prevalence of bullying across countries because of differences in the methodologies employed and different cut-offs used to identify bullies or victims, large studies suggested that $10-30 \%$ of students are frequently involved in bullying as perpetrators and/or victims (e.g., Eslea et al. 2004; Smith et al. 1999). Similar figures have been reported for Italian schools (Vieno et al. 2008). More recently, Molcho and colleagues (2009) demonstrated, through a cross national trend study (in which, however, Italy was not included), a clear and significant decrease in involvement in bullying behaviour in most European (except for Greece and England) and North American countries from 1994 to 2006. The authors suggested that this decrease was likely due to an increase in awareness about the problem and of efforts to counteract it.

Given the severity of outcomes associated with involvement in bullying (as perpetrators or victims) and the resources spent in an effort to reduce its prevalence, it is important to investigate trends in the occurrence of bullying by national studies. Indeed, during the last decade awareness about bullying and its serious effects has progressively increased among parents and school personnel, and in the media as well, which has produced a greater demand for anti-bullying policies and interventions. For several years, however, in Italy there has been only local initiatives (Gini 2004; Menesini et al. 2003). In 2007, however, the Italian Ministry of 
Education launched a National campaign by issuing a directive called DM n.16 (February $5^{\text {th }}$, 2007) _"National lines and actions for bullying prevention" ("Linee di indirizzo generali ed azioni a livello nazionale per la prevenzione e la lotta al bullismo" - DM n.16, February $5^{\text {th }}$, 2007). For the first time, this document stated the necessity to develop policies and programs to prevent bullying at the national level. To this end, a website was created under the direction of the Ministry of ... (?) to collect and distribute information, documents, materials, and projects about the characteristics of bullying and its prevention, and a counselling service through a free phone number was also made available. Moreover, in each of the 20 regions of the country, an standing Observatory on school bullying was created, under the direction of the Regional School Office. Each Office had the freedom to choose the members of the observatory and to organize its work. For this reason, differences can be found from one region to another.

Beyond the governmental initiatives, since 2008 other Institutions (e.g., the Italian Police) and national associations (e.g., the Italian Pediatric Society; "Telefono Azzurro", a NGO for children's rights; “Arcigay”, the foremost national organization for LGBT rights) have contributed to raise awareness about the phenomenon, for example by disseminating their own materials and guidelines about bullying prevention and offering practical responses to bullying, including phone counselling, and training for teachers and parents.

The current study, therefore, aims at examining trends in Italy in the occurrence of both bullying and victimization at different levels of involvement (i.e., occasional and chronic; see Molcho et al. 2009) using adolescents' responses to three "Health Behaviour in School-aged Children" (HBSC) surveys conducted in 2002, 2006, and 2010, respectively. Similarly to what have been documented for many Western countries (Molcho et al. 2009), we expected to find an overall decrease from 2002 to 2010 in the prevalence of the phenomenon. Furthermore, we hypothesized a stronger decrease of prevalence of bullying and victimization between 2006 and 
2010, as compared to the previous four years, as a result of the relevant changes in policy and bullying prevention efforts occurred at the national level. Finally, in keeping with the studies that found different trends by gender—so-called "gender convergence"—in various negative behaviours (e.g. drunkenness, see Vieno et al. 2013), we explored gender differences in the trends of both bullying and victimization.

\section{Methods}

\section{Procedures}

This study was conducted with samples of Italian middle [u2] and secondary school students drawn from three surveys $(2002,2006,2010)$ of the "Health Behaviour in School-aged Children" (HBSC) project, a trans-national study conducted every four years and carried out in collaboration with the European office of the World Health Organization (Currie et al. 2009). The research protocol included three age groups: 11-, 13-, and 15-year-olds corresponding to the $6^{\text {th }}, 8^{\text {th }}$, and $10^{\text {th }}$ grade (first and third grade of Italian middle [u3]school, and second grade of Italian secondary school). Across the survey years, data were collected via self-report questionnaires during a regular school day, and participants were assured of the confidentiality of their answers.

\section{Participants}

Following the HBSC protocol, participants were chosen through-using a sample clustering approach (Thompson 1999)_: First, the schools were randomly selected from the National School Office's database of all public schools, and then in each school, one class for each age group was selected randomly. Within-Sampling was stratified within each area of the country (northwest, northeast, central and, southern Italy, and-islands), samples were stratifiedin order to represent the distribution of students in grades 6, 8, and 10 (modal ages 11, 13, and 15) and to be representative of the schools' student populations in those areas. The sample includes 
Aatl students in the selected classes were included in the sample. This particular design ensures $\theta$ a sampled population that accurately reflects the referent population. A detailed description of objectives, theoretical framework and methodology of the survey is available elsewhere (Roberts et al., 2009)

\section{INSERT TABLE 1 ABOUT HERE}

Across the three surveys, the questionnaire was completed by a total of 13,174 adolescents and early adolescents Italian students (50.3\% girls). The average-mean age of for each of the three age groups was 11.67 years $(\mathrm{SD}=.39, \mathrm{~N}=4,339), 13.69$ years $(\mathrm{SD}=.37, \mathrm{~N}=$ $4,648)$, and 15.70 years $(\mathrm{SD}=.38, \mathrm{~N}=4,101)$.

\section{Measures}

Data were collected through a self-report questionnaire, devised by the HBSC international group, that focuses on health behaviours of early adolescents and adolescents. Two mandatory questions on bullying and victimization were included in each survey, following a standard definition of bullying (Olweus 1993). The first item assessed bullying behaviour: "How often have you taken part in bullying another student at school in the past couple of months?" The second item assessed bullying victimization: "How often have you been bullied at school in the past couple of months?" Responses were rated on a five-point scale: $1=$ never; 2 = once or twice; 3 = two or three times a month; 4 = about once a week; $5=$ several times a week. Consistent with Olweus' studies (1994) and more recent studies (e.g. Molcho et al. 2009) involvement in bullying was classified as "occasional" and "chronic". Binary outcomes for occasional bullying (and victimization) were based upon responses on "once or twice" vs. "never". Binary outcomes for chronic bullying (and victimization) were "more than two times in the last two months" vs. "twice or less in the last couple of months".

\section{Data analysis}


Prevalence of occasional and chronic bullying and victimization was compared by survey year (and by gender), and the Gamma statistics was used to test the year trend. The Gamma statistic represents a symmetric measure of association between two ordinal variables; it ranges between -1 and 1 . Values close to $+/-1$ indicate a strong relationship (positive or negative) between the two variables. Values close to 0 indicate little or no relationship (Goodman et al. 1972). Moreover, to investigate the gender difference in these trends, the frequency of involvement in bullying [u4]was regressed (through logistic regression) on gender, survey year, and the interaction of the two variables, after controlling for participants' age.

\section{Results}

The first line of table 1 presents the prevalence of occasional victimization by gender. Girls reported the larger decrease-and pronounced decreases in the prevalence of victimization ... $\operatorname{are}[u 5\}$-is evident in particular between 2006 and 2010.

\section{INSERT TABLE 1 ABOUT HERE}

Similar to occasional victimization, decreases in occasional bullying (second line of Table 1) were evident, and resulted very similar for both boys and girls. Again, the largest decreases were found between 2006 and 2010.

The percentage of children [u6]chronically involved in the-victimization decreased over the years from $12.8 \%$ to $6.5 \%$ among boys and from $9.2 \%$ to $4.0 \%$ among girls. As expected with the overall lower prevalence of chronic victimization, the decreases in absolute prevalence of victimization were was smaller than for indices of occasional victimization. However, the relative percentage change [u7]in chronic victims is still higher than 50\% from 2002 to 2010 , again with $\underline{\text { a larger decreases after } 2006 .}$ 
Similar patterns are evident for chronic bullying. Although we found no differences in relative trends (\% of decrease), in absolute terms[u8], decreases in prevalence of chronic bullying in both gender groups were-was more pronounced than that the one reported for chronic victims.

To test for the possible gender convergence in bullying, we ran four logistic regression models, one for each outcome (Table 2). These analyses yielded a significant effect of survey year for all the-dependent variables, thus confirming the trends described above. Moreover, a significant main effect of gender was found (with higher frequencies for both bullying and victimization among boys), along with a significant (?) interaction of gender with survey year for occasional victimization, i.e.- That is, the decrease in victimization was stronger for girls..

\section{INSERT TABLE 2 ABOUT HERE}

\section{Discussion}

The results of the current study showed a general decrease in the prevalence of bullying and victimization in Italy, more evident after 2006. More specifically, rates and trends appear to be similar by gender, except for occasional victimization, with a stronger decrease among girls. As a consequence, gender differences in victimization were smaller in 2002.

In general, in contrast to public opinion and mass media alarms, but in accordance with recent studies in different geographical settings (Molcho et al. 2009), our results revealed a decrease in adolescent bullying in Italy, in particular after 2006. Of course, study like this one cannot establish any causal link between specific interventions and changes in bullying/victimization prevalence. Nonetheless, thanks to the study design employed by the HBSC survey, data presented in the current investigation offer a representative picture of the phenomenon under study in the Italian school-age population. Interestingly, overall the national anti-bullying campaign started in 2007 has been effective not only in raising awareness about the problem, but also in decreasing its prevalence. Future studies adopting a similar design should 
investigate whether these trends over time have had a positive impact also on the consequences of bullying; for example, one could expect a similar decrease in the psychosocial and health problems that too often accompany bullying and victimization (Gini and Pozzoli 2013; Reijntjes et al. 2010; Ttofi et al. 2011).

Regarding the gender convergence hypothesis, our results indicate a significant increase in the "gender gap", but only for occasional victimization. While it is difficult to explain this result without further analyses, it may suggest a different susceptibility of boys and girls to antibullying interventions and the importance of designing evidence-based measures to reduce adolescent bullying that consider gender differences.

\section{Limitations and Strengths}

The present study has some limitations. First, since it considered only three time periods, the stability of the trends could not be clearly determined. Second, only self-report measures of involvement in bullying were used. Self-report measures are very common in bullying research and are usually considered to be valid and reliable, especially for adolescent students (Ladd and Kochenderfer-Ladd 2002). However, possible problems with these instruments are that they require a good level of respondents' self-consciousness and that some bullied children may tend to deny their condition, whereas youths who bully may be sometimes reluctant to admit it. To avoid these problems, future studies should collect information about youths' bullying experiences through multiple independent informants, such as students themselves, their peers within the class, and their teachers or parents.

These limitations notwithstanding, the results from the present study are important for several reasons. The strengths of the study include the use of a large and representative Italian sample and a range of ages across two school levels. Moreover, this is the first study conducted in Italy analysing time trends in bullying among early adolescents and adolescents that evaluated 
their prevalence across gender. Finally, since the current data are part of a multinational study, they will also permit future cross-cultural research on the topic.

In conclusion, findings presented in this paper demonstrate a robust decrease in involvement in bullying in Italy. Although bullying is not eradicated, these findings should send an encouraging message to practitioners in the field and policy makers regarding the efficacy of the prevention programs and about the investment done in the last years in order to prevent these phenomena.

\section{Acknowledgement}

HBSC is a cross-national study co-ordinated from the European Office of WHO. International Co-ordinator for the study: Candace Currie, University of Edinburgh; Data Bank Manager: Bente Wold, University of Bergen; National Co-ordinator: Franco Cavallo, University of Torino. This work was partially supported by Research Grant CPDA103978 from the University of Padova to the authors. The study was partially supported by a intra-mural grant of the University of Padova (2010, prot. CPDA103978).

Conflict of interest. The authors declare that they have no conflict of interest.

\section{References}

Beccaria F, Allaman A (2007) Changes in the consumption of alcoholic beverages in Italy: studies of the decrease in consumption between the 1970s and the 2000s. Contemp Drug Probl 34:183-186.

Currie C, Nic Gabhainn S, Godeau E and the International HBSC Network Coordinating Committee (2009) The Health Behaviour in School-aged Children: WHO Collaborative 
Cross-National (HBSC) Study: origins, concept, history and development 1982-2008. Int J Public Health 54:S131-139.

Ladd GW, Kochenderfer-Ladd BJ. Identifying victims of peer aggression from early to middle childhood: Analysis of cross-informant data for concordance, estimation of relational adjustment, prevalence of victimization, and characteristics of identified victims. Psychol Assess. 2002;14:74-96.

Roberts, C., Freeman, J., Samdal, O., Schnohr, C., Looze, M., Nic Gabhainn, S., \& Iannotti, R. (2009). The Health Behaviour in School-aged Children (HBSC) study: methodological developments and current tensions. International Journal of Public Health, 54(Suppl 2), 140-150. 
Table 1. Rates of occasional victims/bullying, and chronic victims/bullying (\%) among Italian early adolescents and adolescents in 2002,2006 , and 2010 according to gender ${ }^{\mathrm{a}}$

\begin{tabular}{|c|c|c|c|c|c|c|c|c|}
\hline & \multicolumn{4}{|c|}{ Boys N (\%) } & \multicolumn{4}{|c|}{ Girls N (\%) } \\
\hline & 2002 & 2006 & 2010 & $\begin{array}{l}\text { Change } \\
\text { (gamma) }\end{array}$ & 2002 & 2006 & 2010 & $\begin{array}{l}\text { Change } \\
\text { (gamma) }\end{array}$ \\
\hline Occasional victims & $399(21.5)$ & $317(17.9)$ & $202(9.4)$ & $-.305^{* *}$ & $378(18.4)$ & $228(12.5)$ & $125(5.7)$ & $-.403 * *$ \\
\hline $\begin{array}{l}\text { Occasional } \\
\text { bullying }\end{array}$ & 499 (28.9) & $450(26.2)$ & $357(16.1)$ & $-.249 * *$ & $438(21.1)$ & $299(16.4)$ & $240(10.4)$ & $-.275^{* *}$ \\
\hline Chronic victims & $273(12.8)$ & $227(11.4)$ & $130(6.5)$ & $-.227 * *$ & $207(9.2)$ & $136(7.0)$ & $78(4.0)$ & $-.272 * *$ \\
\hline Chronic bullying & $400(18.8)$ & $280(14.0)$ & $204(8.4)$ & $-.299 * *$ & $182(8.0)$ & $128(6.6)$ & $98(4.1)$ & $-.236 * *$ \\
\hline
\end{tabular}

$* \mathrm{p}<.05 ; * * \mathrm{p}<.01 ; \# \mathrm{p}<.10$

${ }^{a}$ We expressed the magnitude of changes (trend) in terms of gammas. Values close to an absolute value of 1 indicate a strong relationship between the two variables

Table 2. Gender, age, survey year (2002, 2006, 2010), and interaction (gender*survey year) as determinants (odds Ratio, and 95\% IC) of different forms of involvement in bullying for the total sample

\begin{tabular}{lcccc}
\hline Variable & Occasional victims & Occasional bullying & Chronic Victims & Chronic Bullying \\
\hline Gender $(1=$ female $)$ & $.676(.604-.757)^{* * *}$ & $.599(.545-.658)^{* * *}$ & $.621(.541-.713)^{* * *}$ & $.417(.367-475)^{* * * *}$ \\
Age & $.837(.810-.865)^{* * *}$ & $1.015(.987-1.044)$ & $.851(818-886)^{* * *}$ & $1.037(1.001-1.074)$ \\
Survey Year & $.867(.853-.882)^{* * *}$ & $.907(.895-.920)^{* * *}$ & $.903(.885-922)^{* * *}$ & $.905(.888-923)^{* * *}$ \\
Gender*Survey & $.932(.882-985)^{* *}$ & $.608(.942-1.035)$ & $.944(.902-1.001) \#$ & $1.042(.978-1.110)$ \\
year[u9] & & & &
\end{tabular}

$* \mathrm{p}<.05 ; * * \mathrm{p}<.01 ; \# \mathrm{p}<.10$ 